\title{
LA ELECCION DE TECNICA \\ EN EL CULTIVO TRIGUERO \\ Y EL ATRASO DE LA AGRICULTURA \\ ESPAÑOLA A FINALES DEL SIGLO XIX *
}

JAMES SIMPSON

\section{INTRODUCCION}

La interpretación tradicional de la agricultura española considera que durante medio siglo antes de la guerra civil hubo pocos cambios en la productividad de los factores de producción. Además, la falta de cambios en la agricultura se ha considerado muchas veces, junto con los bajos niveles de vida de muchos productores y una demanda doméstica insuficiente para estimular la producción industrial, como un círculo vicioso del «estancamiento agrícola». Las causas principales de la baja productividad en el sector agrario han sido atribuidas a problemas estructurales, como el latifundio y el minifundio, y a los inadecuados métodos de cultivo, resultado de inversiones de capital insuficientes.

Comparando a España con otros países de Europa, no se puede dudar del bajo nivel tecnológico encontrado en la agricultura española en vísperas de la guerra civil. Sin embargo, varios estudios han mostrado que la agricultura no estuvo en situación de estancamiento. En concreto, los cambios en los tipos de cultivo y la intensidad de las rotaciones de cereales y leguminosas aumentaron la productividad de la tierra ${ }^{1}$. Estas mejoras en la organización de la producción fueron acompañadas, en algunos casos, por un aumento del capital utilizado. Por ejemplo, en la construcción de nuevos sistemas de regadío, o en un aumento en la cantidad de abonos ${ }^{2}$, y, como vamos a examinar aquí, en cambios de los tipos de maquinaria utilizada. Estos ejemplos indican que los agricultores españoles, en algunos casos, estuvieron dispuestos a cambiar

* Quiero agradecer a Malcolm Falkus, Pedro Fraile, Domingo Gallego, Gabriel Tortella y Santiago Zapata sus útiles comentarios y críticas sobre una versión anterior. Los errores son responsabilidad del autor.

1 GEHR (1985); L. Prados (1986); J. Simpson (1985), pp. 74, 336-340.

${ }^{2}$ El ritmo en el crecimiento de la superficie de regadío fue de un 0,7 por 100 entre 1904-1932. La cantidad de nitrógeno, anhídrido fosfórico y óxido de potasio utilizados aumentó a un ritmo del 2,2 por 100 entre 1892 y 1933; los abonos minerales aumentaron su contribución del total de un 2,6 por 100 hasta 32,9 por 100 . Calculado a partir de J. Jiménez Blanco (1986), cuadro 19, y D. Gallego (1986), cuadro 5. 
los sistemas de producción tradicionales e invertir en el sector. Entonces, la cuestión que se plantea no es por qué no hubo cambios en los métodos productivos, sino ¿por qué no fueron más generalizados dichos cambios? En este artículo se intenta obtener una respuesta general a esta pregunta, mediante un examen de las técnicas alternativas, con respecto a la mecanización de la producción triguera. El artículo tiene tres partes: primera, un examen breve de los tipos de cambios en la tecnología y el crecimiento agrícola en varios países; segunda, un análisis de la estructura de costes de la producción del trigo, en las provincias más importantes de España en 1886/90, y, por último, un estudio detallado de los varios métodos disponibles para realizar las tareas agrícolas del trigo y un intento para explicar el empeño de muchos productores de seguir con «bajos» niveles tecnológicos.

\section{LA TECNOLOGIA AGRARIA: LA EXPERIENCIA HISTORICA}

La experiencia histórica de la agricultura en el Japón y los Estados Unidos, entre 1880 y 1930, mostró un crecimiento anual de producción no muy diferente $(1,62$ y 1,44 por 100 , respectivamente), pero obtenido de dos maneras muy distintas (cuadro 1). Mientras en Japón la media de tierra por varón empleado en el sector fue solamente de 0,66 hectáreas en 1880 , la cifra en Estados Unidos fue de 25,4 hectáreas, 40 veces más grande, aumentando la diferencia durante el medio siglo siguiente a casi 45 veces. Japón, después de unos intentos sin éxito de aplicar la tecnología estadounidense en su agricultura a finales del siglo XIX, consiguió sus niveles de crecimiento por medio de una tecnología de aumento biológico de los rendimientos, en su mayor parte por medio de fuertes inversiones en regadío ${ }^{3}$. En Estados Unidos, por contraste, el crecimiento fue obtenido por el desarrollo de la tecnología mecánica. En conclusión, los cambios en la tecnología pueden afectar a los rendimientos de la tierra y/o de la mano de obra, y los métodos elegidos por el agricultor, normalmente, vienen determinados por los precios de los factores de producción.

El ritmo de crecimiento de la agricultura española, en $1886-90$ y 1930 , no se diferenció del de los otros países que se muestran en el cuadro 1. Sin embargo, en este cuadro observamos una diferencia importante, y es que el caso español tenía unos bajos niveles de productividad por unidad de tierra y por mano de obra. Japón, por ejemplo, tenía una productividad de mano de obra peor que la de España, pero la de la tierra era 4 ó 5 veces superior. Por contraste, en los Estados Unidos la producción de la tierra era más baja

\footnotetext{
${ }^{3}$ H. P. Binswanger (1984), p. 7.
} 


\section{CUADRO 1}

El crecimiento agrario en varios países, $1880-1930$

\begin{tabular}{|c|c|c|c|c|c|c|c|}
\hline & $A \tilde{n} \overline{o s}$ & España & Alem. & Fran. & R. U. & USA & Japón \\
\hline 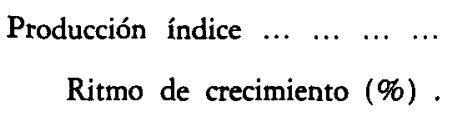 & $\begin{array}{l}1880 \\
1930\end{array}$ & $\begin{array}{l}100 \\
155 \\
0,88\end{array}$ & $\begin{array}{l}100 \\
192 \\
1,31\end{array}$ & $\begin{array}{l}100 \\
146 \\
0,76\end{array}$ & $\begin{array}{l}100 \\
111 \\
0,21\end{array}$ & $\begin{array}{c}100 \\
204 \\
1,44\end{array}$ & $\begin{array}{l}100 \\
223 \\
1,62\end{array}$ \\
\hline $\begin{array}{l}\text { Producción por trabajador (con- } \\
\text { vertida en unidades de trigo) } \\
\text { Incremento }(\%) \\
\text { (\%) }\end{array}$ & $\begin{array}{l}1880 \\
1930\end{array}$ & $\begin{array}{l}2,41 \\
5,10 \\
1,51\end{array}$ & $\begin{array}{c}7,9 \\
16,0 \\
1,42\end{array}$ & $\begin{array}{c}7,4 \\
13,2 \\
1,16\end{array}$ & $\begin{array}{r}16,2 \\
20,1 \\
0,43\end{array}$ & $\begin{array}{c}13,0 \\
22,5 \\
1,10\end{array}$ & $\begin{array}{l}1,9 \\
4,6 \\
1,79\end{array}$ \\
\hline $\begin{array}{l}\text { Producción por hectárea tierra } \\
\text { cultivada } \\
\text { Incremento }(\%) \\
\text { Inidades de trigo) }\end{array}$ & $\begin{array}{l}1880 \\
1930\end{array}$ & $\begin{array}{l}0,66 \\
0,89 \\
0,60\end{array}$ & $\begin{array}{l}1,25 \\
2,47 \\
1,37\end{array}$ & $\begin{array}{l}1,06 \\
1,50 \\
0,70\end{array}$ & $\begin{array}{l}1,10 \\
1,18 \\
0,14\end{array}$ & $\begin{array}{l}0,51 \\
0,56 \\
0,16\end{array}$ & $\begin{array}{l}2,86 \\
5,06 \\
1,15\end{array}$ \\
\hline \begin{tabular}{rrrrrrr} 
Tierra cultivada & por & \multicolumn{3}{c}{ trabajador } \\
(hectáreas) & $\ldots$ & $\ldots$ & $\ldots$ & $\ldots$ & $\ldots$ & $\ldots$ \\
& & & & & & \\
Incremento & $(\%)$ & $\ldots$ & $\ldots$ & $\ldots$
\end{tabular} & $\begin{array}{l}1880 \\
1930\end{array}$ & $\begin{array}{l}3,63 \\
5,70 \\
0,90\end{array}$ & $\begin{array}{l}6,34 \\
6,46 \\
0,04\end{array}$ & $\begin{array}{l}6,96 \\
8,80 \\
0,47\end{array}$ & $\begin{array}{c}14,7 \\
17,0 \\
0,29\end{array}$ & $\begin{array}{c}25,4 \\
40,5 \\
0,94\end{array}$ & $\begin{array}{l}0,66 \\
0,91 \\
0,64\end{array}$ \\
\hline
\end{tabular}

Nota: Producción significa producto bruto del sector agrario.

Fuentes: H. P. Binswanger y V. W. Ruttan (1978), tablas 3-1 y 3-2; España: calculado en base de GEHR (1983 y 1985).

que la española, pero la de la mano de obra era mucho más alta (aproximadamente, 4 ó 5 veces más). España tenía la segunda peor productividad de los seis países en los dos factores de producción.

El énfasis de este artículo está en la mecanización de la producción, que afectó a la productividad de trabajo más que a la de la tierra. Entonces solamente se examina un aspecto de los cambios posibles en el campo español y en el contexto de un solo producto. Pero las conclusiones alcanzadas, en concreto la importancia de las condiciones locales y el tamaño de la propiedad en la selección de la maquinaria más adecuada, tendría la misma importancia con otros productos y otros cambios en la producción. 


\section{LA RENTABILIDAD DEL TRIGO EN ESPAÑA EN 1886-90}

El trigo fue el cereal más importante en España durante todo el siglo XIX y contribuyó en un 22,8 por 100 al total del producto agrario en 1900 . En esta fecha el trigo ocupó, aproximadamente, la mitad de la superficie de cereales y leguminosas, es decir, unos 3,79 millones de hectáreas sembradas ${ }^{4}$. Con la excepción del norte del país, el trigo era el cereal más importante en la dieta de los españoles en casi toda la Península.

Aunque parece que no hubo cambios importantes en los rendimientos del trigo o en los métodos de cultivo entre 1800 y 1880 , tres factores cambiaron la agricultura española significativamente en esta época. En primer lugar, la desamortización y las reformas institucionales dejaron a los propietarios con pleno control sobre sus tierras y, a su vez, la creación de un sistema de propiedad privada facilitó a éstos -en teoría, por lo menos- la posibilidad de llevar al máximo sus beneficios cuando cambiasen los costes de los factores de producción y las oportunidades del mercado. Segundo, el crecimiento de la población, de 10,5 millones en 1797 a 17,5 millones en 1887 , produjo un desplazamiento de las curvas de demanda para el trigo y la tierra hacia la derecha, y un desplazamiento hacia la derecha de la oferta de mano de obra ${ }^{5}, y$, por último, el crecimiento del mercado interior aumentó el nivel de competencia entre los productores nacionales ${ }^{6}$.

En contraste, el arancel del 1891 y la depreciación de la peseta redujeron la competencia extranjera en los mercados domésticos y protegieron a la producción triguera nacional de las consecuencias de la caída de precios mundial ${ }^{7}$. Aunque esta política comercial aumentó la capacidad relativa de la agricultura para retener mano de obra, fueron los productores con mayores rendimientos los que vieron subir sus beneficios más que los pequeños campesinos ${ }^{8}$. Por eso, la primera etapa aquí ha sido calcular la rentabilidad de la producción de trigo a nivel provincial, durante los años 1886-90, usando como fuente el Avance estadístico del cultivo cereal y leguminosas asociados

- GEHR (1983), pp. 243 y 247.

${ }^{5}$ Como todo este crecimiento de la población fue alimentado por la producción doméstica $\mathrm{y}$, al mismo tiempo, España aumentó las exportaciones de otros productos, como vino, aceite de oliva y naranjas, se puede suponer que hubo un aumento significante en el producto total del sector agrario.

6 A finales de los años 1880 , aproximadamente un 25 por 100 de la producción neta del trigo era transportada por ferrocarril. A. Gómez Mendoza (1982), cuadro 6.1.

${ }^{7}$ Por ejemplo, con un índice de precios del trigo de 100 en 1870-79, el índice en Gran Bretaña cayó a 58,3 durante 1885-1913, el precio «mundial» a 65,6 y el precio español a 96,6. Calculado a partir de GEHR (1980), cuadro 14, y W. A. Lewis (1978), Appendix IV.

A. M. Bernal (1984), p. 290. 
en España ${ }^{9}$ (para los métodos, véase Apéndice). Para simplificar la discusión, este artículo trata solamente de la producción del trigo en rotaciones extensas (dos años o más) y de las provincias que tuvieron rendimientos bajos o medios (véase mapa 1). Los efectos de excluir las 10 provincias de altos rendimientos tiene poca importancia, porque constituyeron solamente el 6 por 100 de la producción nacional en 1886-90, y el cultivo del trigo en rotaciones anuales, en las provincias incluidas en este estudio, fue escaso.

En el cálculo de los beneficios anuales (mapa 2 y cuadro 2) es importante notar que no está incluida la provisión para impuestos, amortización de capital (herramientas, animales, etc.) o el coste de la tierra (interés o renta). Tam-

\section{MAPA 1}

Rendimientos de trigo/bectárea (QM), 1886-90

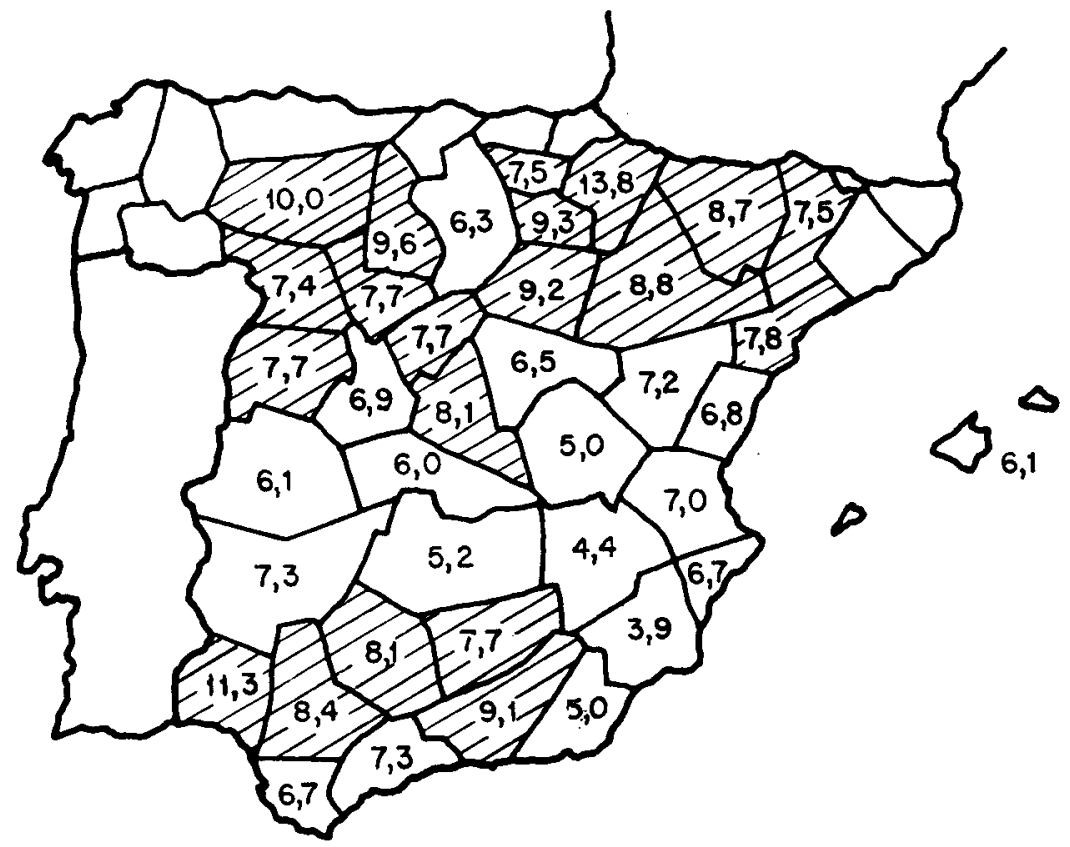

Fuente: Véase Apéndice.

' Dirección General de Agricultura, Industria y Comercio, Avance estadístico del cultivo cereal y leguminosas asociados en España, Madrid, 1891, 3 vols. En adelante, Avance cereal. 
MAPA 2

Beneficios por hectárea/año, $1881-90$

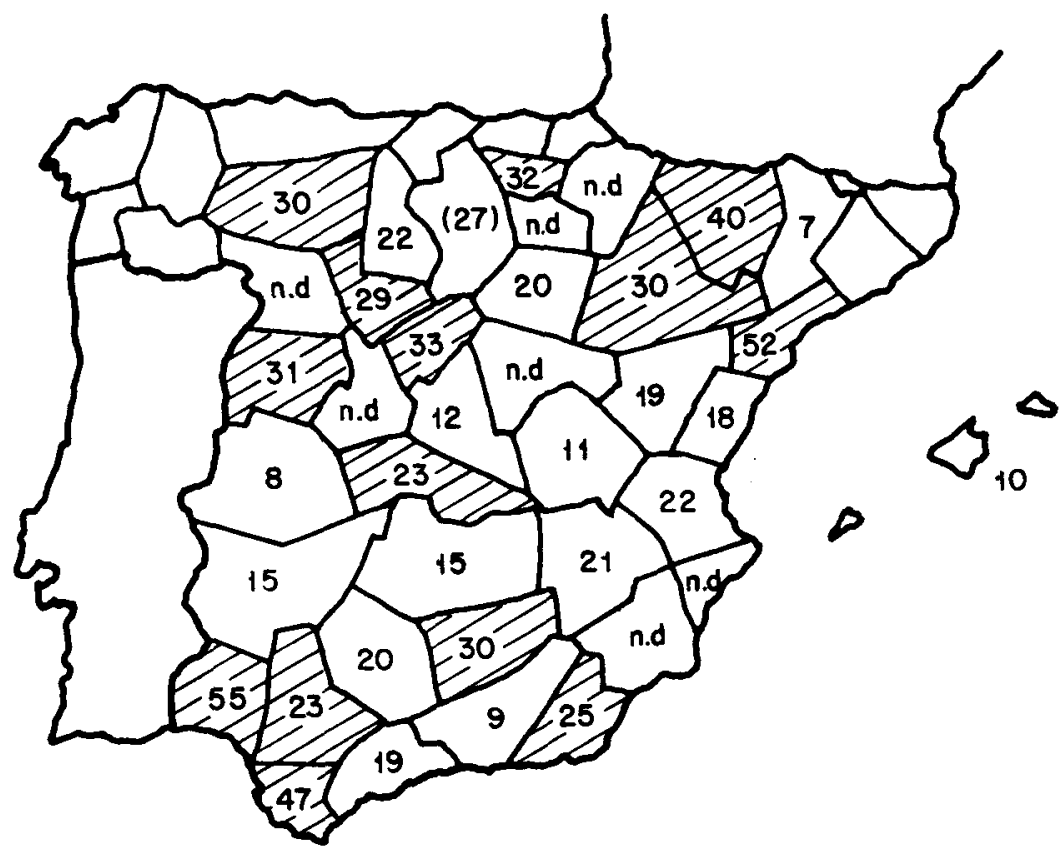

Fuente: Cuadro 2.

bién han sido excluidos los efectos económicos de sembrar otro(s) cultivo(s) en la rotación. Por último, la fuente solamente habla de salarios, cuando en las pequeñas unidades de producción la fuerza de trabajo no era remunerada, ya que venía proporcionada por mano de obra familiar. Por lo tanto, los resultados calculados solamente muestran una parte de la situación triguera en las provincias españolas a finales de la «crisis agrícola».

El cuadro 2 muestra las ganancias y pérdidas en la producción triguera y los costes principales del cultivo. De las 38 provincias iniciales, excluimos las provincias de Alicante, Avila, Guadalajara, Logroño, Murcia, Navarra y Zamora por falta de información o porque los costes presentados se refieren solamente a sistemas intensivos ${ }^{10}$. En el mapa 2 los beneficios/pérdidas por

10 Tampoco son demasiado fiables todos los datos de las otras provincias. Burgos, por ejemplo, muestra una pérdida antes de calcular los impuestos o la renta, y los beneficios por hectárea más altos de España se dan en Almería. 


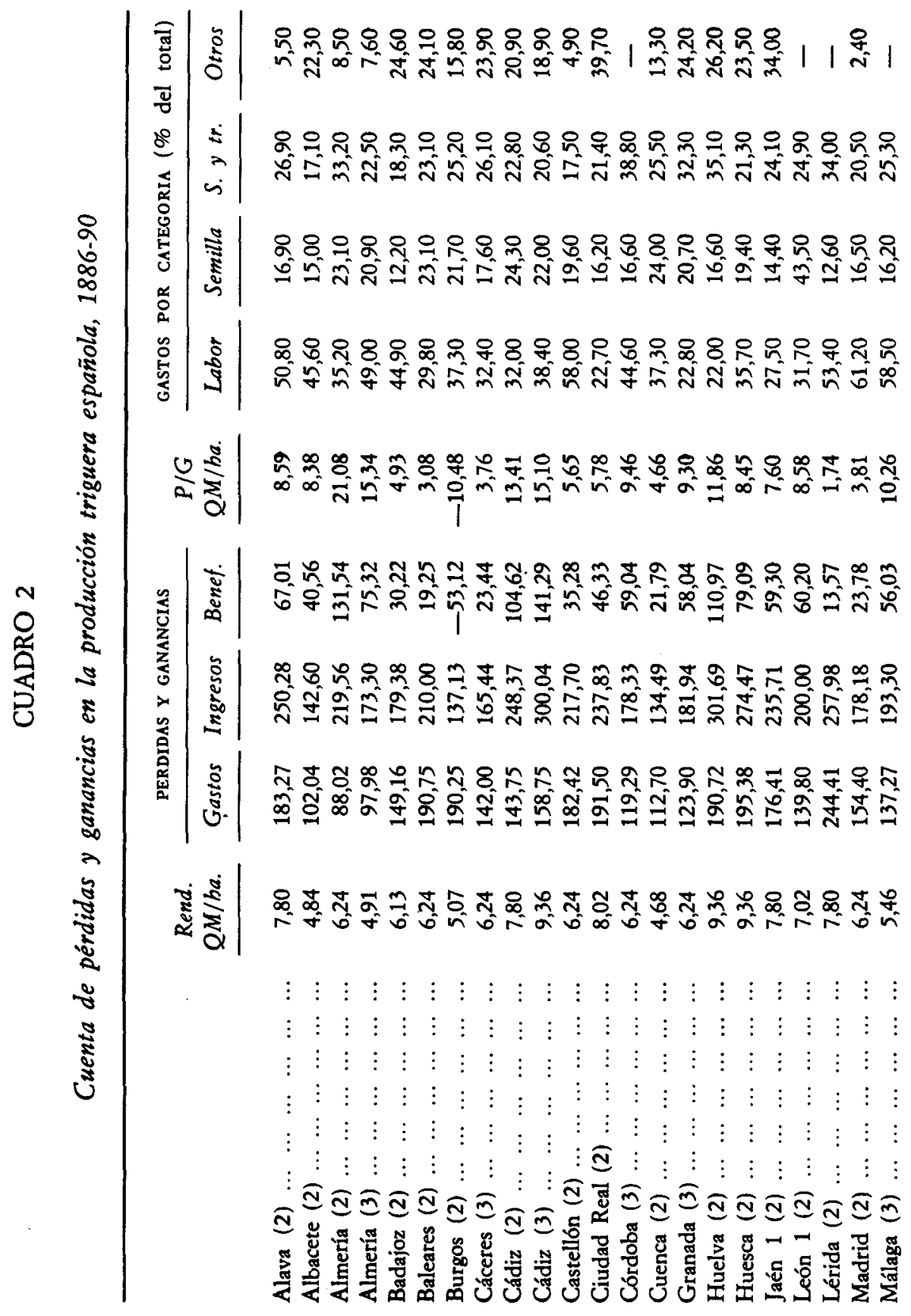




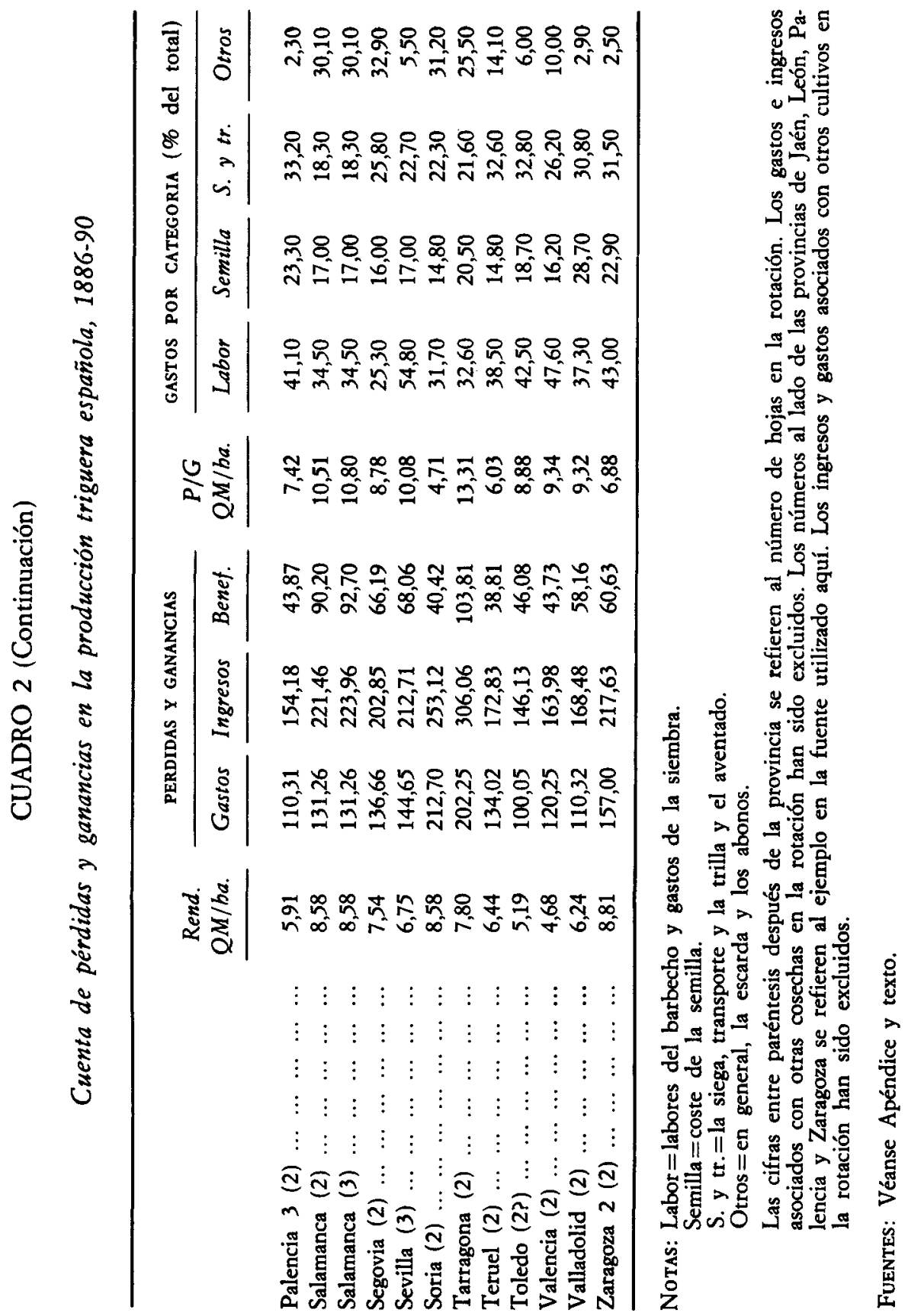


quintal métrico y provincia (cuadro 2) han sido multiplicados por los rendimientos por hectárea (Apéndice) y divididos por los números de rotaciones, para obtener un valor anual de la cosecha del trigo. En el mapa 2 se ve que los beneficios anuales por hectárea fueron más altos en Andalucía, en el noreste (Huesca, Zaragoza y Tarragona) y en el noroeste de Castilla la Vieja. Una gran superficie del centro de España (Extremadura, Castilla la Nueva y el País Valenciano) reúne unos bajos rendimientos con bajos beneficios. Fue precisamente en las regiones de altos beneficios, muchas veces asociadas con grandes superficies de la producción, donde hubo varios intentos limitados de introducir nuevos métodos de siega y trilla, durante la segunda mitad del siglo XIX.

\section{LA PREFERENCIA TECNICA}

De los cuatro grupos de coste que se muestran en el cuadro 2 , los tres primeros: la preparación de la tierra y la siembra, la semilla y la siega, la trilla y el aventado eran esenciales para la producción y la venta del producto, y aquí examinaremos las posibilidades técnicas de los productores. En contraste, los «otros gastos», en general el abono y la escarda, tenían importancia más bien en el aumento de los rendimientos de la tierra, y no las estudiamos.

\section{A) La preparación de la tierra y el uso de animales}

Para los contemporáneos era difícil establecer una relación funcional entre el cultivo y el rendimiento, dado que éste estaba influido por una multitud de factores como el tipo de tierra, el clima, la fuente de energía, la habilidad del cultivador, etc. Normalmente, tras un arado profundo sobre el barbecho se hacían dos o tres rejas de menos intensidad. Como se puede apreciar en el cuadro 2, estas operaciones eran relativamente caras, y en ocasiones llegaron al 50 por 100 o más de los gastos totales de producción. El cultivador tenía que tomar tres decisiones técnicas: el tipo de arado, los animales de tiro y los métodos de siembra.

Arados. El mejor arado dependía no solamente del tipo de tierra y cosecha sembrada, sino de la época de arar. Tradicionalmente, el arado "romano" o «común» valía para varios tipos de trabajo, como el propio de arar y las labores complementarias; por lo tanto, la sustitución completa de este instrumento por otros exigía la compra de varias máquinas (vertederas, extirpadores, cultivadoras o gradas). Entonces, la compra de un arado «moderno», como 
la vertedera, no significaba necesariamente el abandono del arado común en otros tipos de trabajo, y esto explica parcialmente la alta proporción de arados comunes, casi dos tercios del total, en el primer censo de herramientas de $1932^{11}$. Pero quizás fue el uso del arado común para las labores del alzar, en vez de una vertedera, lo que recibió las críticas más fuertes de los coetáneos, porque el arado común trabajaba a poca profundidad y la reja remueve la tierra sin volverla. A finales del siglo xIx el uso de la vertedera se da en pocos sitios, aunque, según el censo de 1932, había una vertedera por cada 10,8 hectáreas sembradas en todo el país ${ }^{12}$. Podemos citar dos posibilidades para esta lenta difusión: la cuestión del coste y de la reparación. Con respecto a lo primero, en un cálculo hecho en la provincia de Sevilla a finales del siglo $\mathrm{xIX}$, vemos lo siguiente ${ }^{13}$ :

\begin{tabular}{|c|c|}
\hline & Ptas/ba. \\
\hline \multicolumn{2}{|l|}{ Con el arado común (con mulas) } \\
\hline 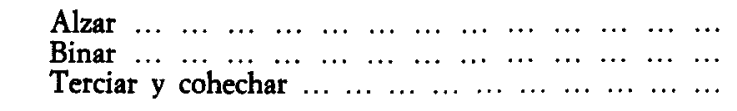 & $\begin{array}{r}11,71 \\
9,98 \\
8,97\end{array}$ \\
\hline $\begin{array}{lllllllllllll}\text { Total } & \ldots & \ldots & \ldots & \ldots & \ldots & \ldots & \ldots & \ldots & \ldots & \ldots & \ldots & \ldots\end{array}$ & 30,66 \\
\hline \multicolumn{2}{|l|}{ Con el arado modificado de vertedera (con mulas) } \\
\hline 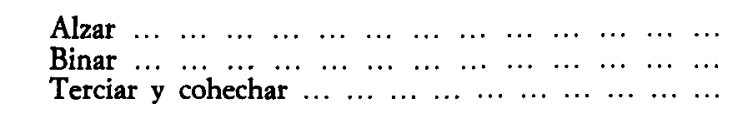 & $\begin{array}{l}17,55 \\
15,53 \\
12,64\end{array}$ \\
\hline 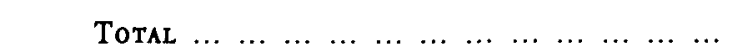 & 45,72 \\
\hline
\end{tabular}

Un 5,4 por 100 del incremento en los costes estaba asociado directamente al uso de la vertedera, el resto era atribuido a un aumento en la demanda de energía animal. Suponiendo que el caso de Sevilla fuese representativo, una clave para el ritmo de difusión aparece en el precio de la fuerza animal, y, como veremos más adelante, los cambios en la productividad en este área quizás permitieron el mayor uso de la vertedera. Respecto a las reparaciones, un coetáneo notó que el uso general de los arados comunes no fue debido a que se ignorasen los «instrumentos modernos», sino a

1 Ministerio de Agricultura (1933), pp. 318-319.

12 Están incluidos todos los cereales y leguminosas, olivos y viñedos. El número de vertederas era de 1.222.788. Ibidem, pp. 296-297, 318.

13 E. Noriega y Abascal (1897), pp. 127-130. 
su extremada sencillez, la facilidad con que se conduce al campo colocado sobre el yugo y arrastrando el extremo del timón al andar la yunta, su fácil manejo, su baratura, la facilidad de construirse y de componerse en casos de rotura por cualquier herrero o carpintero de la última aldea, y hasta por el mismo labrador, son circunstancias que explican su preponderancia en el cultivo en España ${ }^{14}$.

La falta de centros de distribución también contribuía a la resistencia a cambiar de los agricultores. En la provincia de Tarragona, por ejemplo, no había un fabricante de vertederas y los cultivadores tenían que ir a Barcelona o importarlas del extranjero ${ }^{15}$.

La fuerza animal. El factor más controvertido, respecto a las decisiones de los productores, fue, como lo ha sido desde el siglo xvi o antes, la elección entre los bueyes o mulas ${ }^{16}$. Se puede sostener que muchas veces un animal tenía una ventaja sobre el otro, según las condiciones diferentes del terreno, clima, tamaño de la parcela y acceso o no a los pastos ${ }^{17}$. Además, los animales no eran usados solamente en tareas agrícolas, sino también en transportes ${ }^{18}$. Por último, los bueyes fueron más baratos $\mathrm{y}$, además, se vendían para carne, factor importante para los propietarios que solamente empleaban sus animales una parte del año ${ }^{19}$.

La sustitución de bueyes (o vacas) por mulas dependería, entonces, de una gran variedad de factores. En el cuadro 3 se muestra el peso relativo de la mula, como fuente de energía en la agricultura, para los años en que tenemos datos. En el cuadro se puede ver que, aunque hay claras distribuciones

14 P. Muñoz y Rubio (1886), pp. 34-35.

${ }^{15}$ Exposición Vinícola Nacional de 1877 (1878-79), p. 336.

16 El caballo tuvo poca importancia en la agricultura, mientras que el asno fue indispensable para una gran variedad de trabajos, sobre todo en las fincas pequeñas.

${ }_{17}$ Los bueyes fueron utilizados para labrar en las regiones con abundancia de pastos y heno, la tierra dividida en pequeñas parcelas cerca de la cuadra; las mulas, en fincas más grandes, tierras más ligeras y llanas y pastos escasos. Entonces, a finales del siglo XIX, en provincias como Palencia, León o Huesca, la mula fue el animal dominante en los llanos, y los bueyes en las sierras. Dirección General de Agricultura (1892), Palencia, 2, p. 145; León, 2, p. 108; Huesca, 2, pp. 351-352.

${ }_{18}$ Aquí las mulas fueron usadas en distancias largas o por los peores caminos como bestias de carga; los bueyes, por causa de su mayor fuerza, podían tirar una carga más pesada.

19 .... cuando terminadas las faenas del cultivo se relegan los animales a huelgas forzosas, la alimentación consumida durante ellas, que no se convierte en trabajo, se transforma en carne, y no experimenta, por lo tanto, el ganadero pérdida ninguna». Ibidem, Cáceres, 1 , p. 142. El uso de la vaca también tenía la ventaja en que podía parir durante la estación muerta y suministrar leche para el consumo local (ibidem, León, 2, p. 109, en la sierra). Sin embargo, la capacidad de trabajo de una vaca era tres cuartos menor que la de un buey (ibidem, Palencia, 2, p. 148). 


\section{CUADRO 3}

La importancia relativa de la mula como fuerza animal de tracción

\begin{tabular}{|c|c|c|c|}
\hline & 1865 & 1891 & 1933 \\
\hline 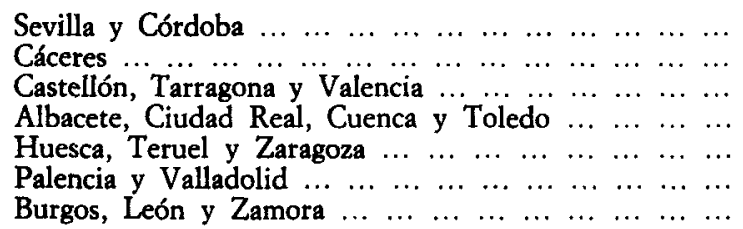 & $\begin{array}{l}31,66 \\
21,82 \\
93,84 \\
77,17 \\
74,16 \\
62,90 \\
11,61\end{array}$ & $\begin{array}{l}34,71 \\
27,70 \\
96,69 \\
\text { n. d. } \\
\text { n. d. } \\
\text { n. d. } \\
\text { n. d. }\end{array}$ & $\begin{array}{l}64,44 \\
44,61 \\
96,98 \\
94,08 \\
83,41 \\
84,01 \\
28,80\end{array}$ \\
\hline
\end{tabular}

Nota: Cifras obtenidas dividiendo el número de mulas por los de bueyes, vacas y mulas empleados en tareas agrícolas.

Fuentes: Junta General de Estadística (1868), pp. 180-181 y 184-185; Dirección General de Agricultura (1982), pp. 7, 34, 42, 50, 57 y 72; Ministerio de Agricultura (1934), pp. 72, 75-78.

geográficas distintas de los varios tipos de ganaderia en cada región estudiada, había una tendencia a incrementar el uso de la mula como fuerza animal.

El resultado de la sustitución del ganado vacuno por mular aumentó la cantidad de trabajo obtenido por unidad de tiempo en las tareas agrícolas. Por ejemplo, en Soria, durante el tiempo que una yunta de mulas necesitaba para arar una hectárea de tierra, una yunta de vacuno hubiera hecho solamente 67 por 100 de la superficie; con ganado caballar, un 75 por 100 , y con asnal, un 47 por $100^{20}$. En Sevilla, las obradas necesarias para la alza y la bina sementera eran 10,19 con el arado común y bueyes y 8,30 con una vertedera y mulas ${ }^{21}$. Entonces, el aumento en la demanda de fuerza animal, señalado en la página como asociado con la introducción de la vertedera, no hubiera existido si hubiera habido también un cambio en los tipos de animales. Para determinar las consecuencias de la sustitución de animales con respecto de los gastos totales tenemos dificultades no porque no existan fuentes disponibles, sino, más bien, para determinar la demanda de trabajo (dentro y fuera del sector) y, en el caso del vacuno, el valor de los subproductos. Como el otoño era una de las dos épocas de máxima demanda (la otra época era la de la cosecha de cereales) para el ganado de labor, la mayor productividad de los animales permitía a los agricultores mejorar su trabajo. Sin embargo, los

\footnotetext{
${ }^{20}$ La Ganaderia (1891), Soria, I, p. 569.

${ }^{21}$ Noriega y Abascal (1897), pp. 112 y 127-129.
} 
mayores costes de alimentación de la mula y la falta de producción de otros beneficios, aparte de fuerza de labor (incluyendo su esterilidad), explican su lenta difusión en varias partes del país donde existían pastos baratos para los bueyes ${ }^{22}$.

\section{B) La siembra}

Dado el alto coste de la semilla, la siembra se hacía muchas veces por trabajadores de confianza, y los salarios tendían a ser más altos que los de otros tipos de trabajos con esfuerzo físico similar ${ }^{23}$. Para el agricultor, el uso de una sembradora tiene dos ventajas potenciales: una mejor utilización de la semilla, resultado de la regularidad de dispersión, y la profundidad de la operación. La sembradora estadounidense de nuevas rejas, ensayada en tierra de regadío en la provincia de Zaragoza, operaba a una velocidad de 4 hectáreas al día, cuando la que se ensayó en Córdoba conseguía 1,5 en diez horas, «dejando el trigo a 3,50 ó 4 centímetros de profundidad y admirablemente distribuido» ${ }^{24}$. Era posible sembrar a voleo a estas velocidades, pero el agricultor podía ahorrar en el uso de la semilla usando la sembradora para mayor control de la operación $(0,975 \mathrm{QM} /$ ha. en vez de 1,95 , en Huesca, y $1,04 \mathrm{QM} /$ ha. en vez de 1,48, en Córdoba). En Huesca, un 93 por $100 \mathrm{de}$ los costes ahorrados correspondieron a la semilla, aunque en Córdoba la cifra fue solamente un 51 por $100^{25}$. Además, las posibilidades de germinación eran mayores dada la profundidad de la siembra.

A finales de la década de 1880 casi no había sembradoras operando en España y el entusiasmo de los agricultores era pequeño. El aparato citado en Huesca había sido ensayado por varias personas en la provincia, pero siguió siendo la única sembradora en operación, al igual que en Córdoba. En Toledo, según el ingeniero agrónomo, algunos agricultores

como el Excmo. Sr. Duque de la Unión de Cuba, el Marqués de Muguiro y otros trataron de introducir su uso, pero sea que los modelos elegidos no se adaptasen a las condiciones del terreno, sea que fueron rechazadas por los capataces y braceros, es lo cierto que ninguna de ellas funciona al presente ${ }^{26}$.

${ }^{22}$ E. Llopis Agelan y S. Zapata han sugerido que algunos campesinos cambiaron el buey o vaca por la mula contra su voluntad, y ello representó un empeoramiento de su nivel de vida. Llopis (1986), pp. 33-34; Zapata (1986), p. 713.

${ }^{23}$ Por ejemplo, el salario en Sevilla era un tercio mayor que el de otro trabajo de similares exigencias físicas. Avance cereal, Sevilla, 3, p. 124.

${ }^{24}$ Avance cereal, Córdoba, 1, p. 403, y Huesca, 2, p. 148.

${ }_{2 s}$ Avance cereal, Córdoba, 1, pp. 401 y 404, y Huesca, 2, p. 148.

${ }^{26}$ Avance cereal, Toledo, 3, p. 297. 
La Dirección General de Agricultura envió varios modelos a distintas provincias en un intento de interesar a los agricultores, pero sin éxito. Por ejemplo, en Teruel, la sembradora norteamericana quedó sin ensayar por «no haber ofrecido terreno alguno, ni las corporaciones ni los particulares» ${ }^{27}$. En Soria, el agrónomo anota que los labradores «ejecutan la siembra a voleo con bastante perfección», y las únicas dos sembradoras entraron a formar parte del Museo Agronómico ${ }^{28}$.

Dado que el mayor ahorro que producía el uso de la sembradora resultaba ser una reducción en las necesidades de semilla, podemos suponer que la difusión de la máquina ocurriría primero en las provincias que utilizaran mayores cantidades de semilla por unidad de tierra. Según el mapa 3, estas regiones, a finales del siglo xIx, se encontraban en el norte de Castilla y León y Aragón. De las 13 provincias que tenían la mayor necesidad de semilla por hectárea sembrada de trigo en 1886-90, 9 se encuentran en la lista de las 13 provincias con mayor densidad de sembradoras en 1932 (264 ha. o menos de trigo sembrado por cada máquina; véase el cuadro 4). Solamente Cádiz (con una máquina por cada 265 ha.), Lérida (1: 445 ha.), Burgos (1: 477 ha.) y Soria ( $1: 1.619$ ha.) están fuera de la lista ${ }^{29}$. Al otro extremo, de las 11 provincias que usaban solamente un hectolitro o menos de semilla/hectárea, en 1886-90, 5 aparecían también en la lista de las 11 provincias con mayor densidad de tierra sembrada por máquina (Albacete, Almería, Jaén, Segovia y Toledo). Podemos, por tanto, concluir que existía una relación importante entre la alta necesidad de semilla, a finales del siglo xIx, y la introducción de las sembradoras. A niveles más bajos de semilla la relación no es tan fuerte, en parte por la relativamente alta concentración de sembradoras en el sudoeste del país (véase mapas 3 y 4 ).

\section{C) La siega}

En España, la siega se realizaba en junio y a finales de agosto, según las condiciones locales. El momento exacto de la recolección era crítico, porque si se hacía demasiado temprano el grano estaba todavía verde y difícil de separar del cascabillo, mientras que en una recolección tardía se arriesgaba la pérdida del grano al caer al suelo. Esta era la época de mayor demanda de mano de obra durante el año, y la oferta regular de trabajo se veía aumentada por grandes cantidades de personas que normalmente no se encuentran

${ }^{27}$ Avance cereal, Teruel, 3, p. 262.

23 Avance cereal, Soria, 3, p. 174.

29 Estas trece provincias representaban 1.254 .010 hectáreas, el 31 por 100 del total, y 14.062 sembradoras, el 83 por 100 del total. 
MAPA 3

La cantidad de semilla/bectárea sembrada, 1886-90

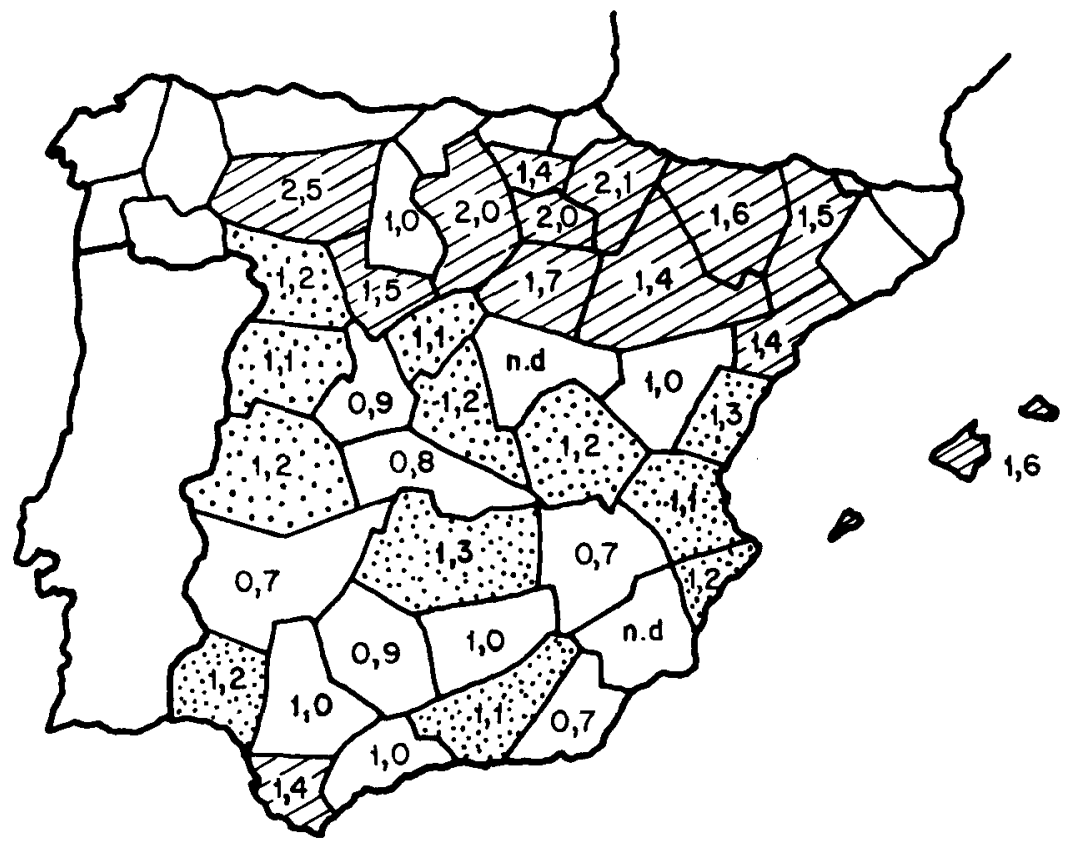

FUENTE: Avance cereal (1891).

en las cifras de población activa del sector. Era la elasticidad de estos trabajadores temporeros (mujeres, niños, mano de obra industrial) la que determinaba los niveles de salarios y la rentabilidad o no de la mecanización. En general, se pueden distinguir tres métodos para cortar el trigo: mediante el uso de la hoz, de la guadaña o de la segadora.

Aunque la manufactura comercial de segadoras existía ya en los años 1830 en Estados Unidos, la industria creció poco hasta la década de 1850, cuando un aumento en el precio del trigo coincidió con un aumento en los gastos de la recolección por métodos tradicionales con respecto a los precios de segadoras. En Andalucía, algunos latifundistas mostraron, a finales de los años 1850, interés en la nueva tecnología, y La Agricultura Española de junio de 1865 hace notar que la provincia de Sevilla disponía de «sesenta y seis segadoras de distintos sistemas: Garret, Wood, MacCormick...» ${ }^{30}$. Pero el interés no estaba

${ }^{30}$ Citada en F. Herán (1980), p. 190. 


\section{MAPA 4}

Número de bectáreas sembradas con trigo por cada sembradora, 1932

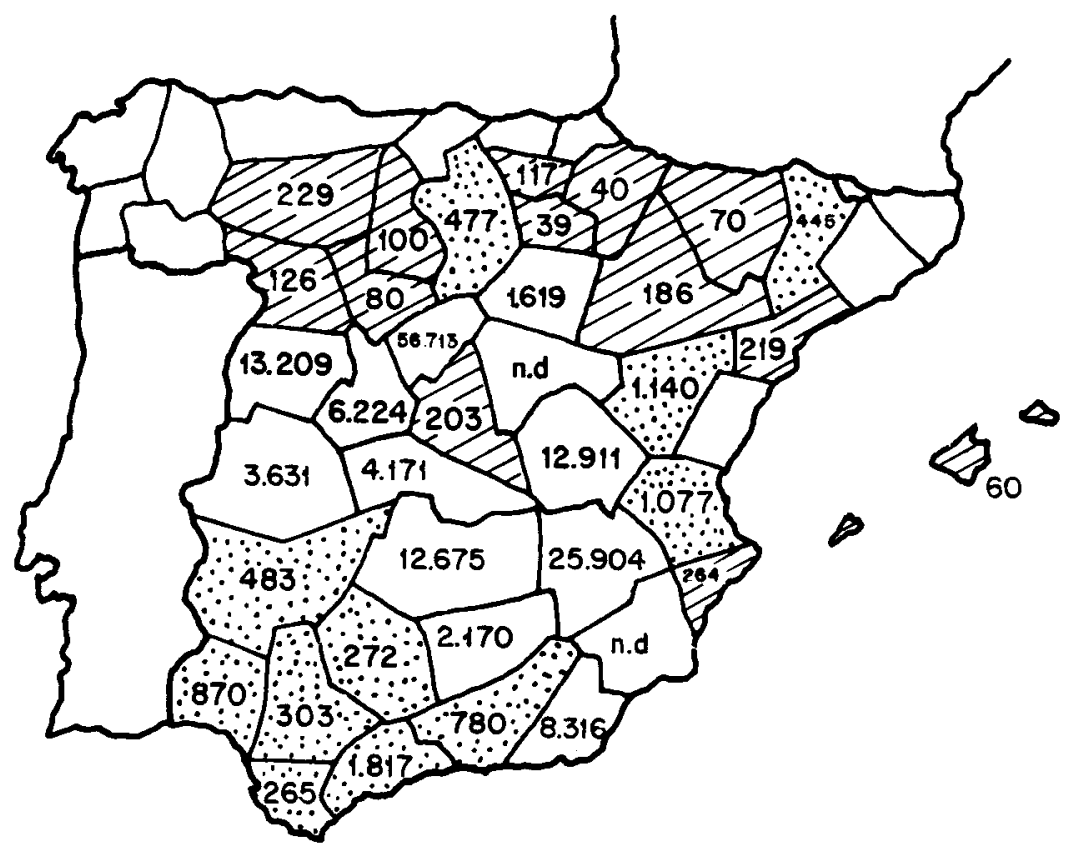

Fuznte: Ministerio de Agricultura (1933), pp. 10 y 319.

limitado a la provincia de Sevilla, porque, en julio del mismo año, el constructor Parsons (asociado con Wood) tuvo 17 pedidos de la provincia de Jaén ${ }^{31}$. Sin embargo, en 1891 , el Avance cereal apuntó solamente "ocho o diez segadoras agavilladoras que poseen algunos propietarios y que solamente las emplean en especiales condiciones y terrenos» en Sevilla'y no menciona ninguna en Jaén ${ }^{32}$. En realidad, y probablemente sólo en Gerona (concretamente en el Ampurdán), Huesca, Navarra, Sevilla y Zaragoza llegaron a 10 o más las segadoras, siendo la concentración mayor en las provincias aragonesas ${ }^{33}$.

"Ibidem, p. 191.

${ }_{32}$ Avance cereal, Sevilla, 3, p. 145.

33 Algunas veces es diff́cil de estar seguro de que no existían errores en las estimaciones o de que el número de máquinas en realidad fluctuó como dicen las fuentes. Por ejemplo, un escritor notó en 1901 que él había tenido una segadora por quince años en Árjona (Jaén), aunque ninguna es mencionada en el Avance cereal de 1890, y que había 
En el cuadro 4 se muestra una comparación de los costes de segar usando métodos tradicionales (la hoz) y con maquinaria «moderna» (segadoras) en las provincias de Huesca, Sevilla y Zaragoza a finales de la década de 1880; se hace un intento de calcular los tamaños mínimos o umbrales de rentabilidad de las explotaciones necesarias para obtener beneficios usando una segadora. El método consiste en dividir todos los costes en fijos y variables, y el punto de equilibrio es:

$$
\text { umbral de rentabilidad }=f /(t-v)
$$

donde $f$ representa los costes fijos y $v$ los costes variables usando una segadora, y $t$ los costes totales usando métodos tradicionales.

El punto de equilibrio o umbral hasta el que la siega con la hoz es más rentable que con la segadora estaba solamente en las 13,31 ó 17,55 hectáreas en Huesca, 14,61 en Sevilla y 11,76 en Zaragoza. Aunque estas cifras se refieren a la superficie sembrada y no a la cultivada, parece que muchas partes en el centro y mediodía de España tenían unidades de producción lo suficientemente grandes y abiertas, con pocos problemas de drenaje y cercados que pudieran estorbar a la maquinaria ${ }^{34}$. Sin embargo, suponer que muchos productores en España eran ineficientes porque no usaron la tecnología que parece la más apropiada es seguramente un error. En el caso de Sevilla, si los costes que se encuentran en el cuadro 4 , que se refieren al año 1864 , se corrigen para el período 1886-90, darán un punto de equilibrio de 26 hectáreas por el método tradicional de segar a jornal y 50 hectáreas cuando es a destajo ${ }^{35}$. Además, si la máquina funciona a un ritmo de menos de $3,50 \mathrm{ha} /$ día como media durante los treinta días de la cosecha, sería más rentable recogerla con la hoz a destajo. Así, parece que los costes relativamente altos de hacer la siega por métodos tradicionales en Huesca, Navarra y Zaragoza estimularon la difusión de la segadora; una oferta suficiente y barata de mano de obra, en otras partes del país, hizo lo contrario. Pero había también otras dificultades para la difusión de la máquina.

Primero está la cuestión de reparación y mantenimiento. Comparándolos con el Medio Oeste, en Estados Unidos, donde a partir de la década 1850

doce segadoras de distintos constructores, solamente en este término, a principios del siglo xx. F. Serrano (1901), p. 177. Huesca parecía la provincia con más máquinas en 1886-90, con doscientas «segadoras sencillas» y unas treinta atadoras. Avance cereal, Huesca, 2, p. 157.

${ }^{3}$ Estas, por ejemplo, son algunas de las razones sugeridas por David por el retraso relativo en el uso de la segadora en Inglaterra con respecto a Estados Unidos. P. David (1975), pp. 233-288.

${ }^{3 s}$ Los precios usados son: siega a destajo, 15,38 ptas/ha.; a jornal, 19,10 ptas/ha.; mulas, 3,5 ptas/día; mano de obra, 2,86 ptas/día, y el coste de una segadora, 825 ptas. Calculado en base de Avance cereal, Sevilla. 


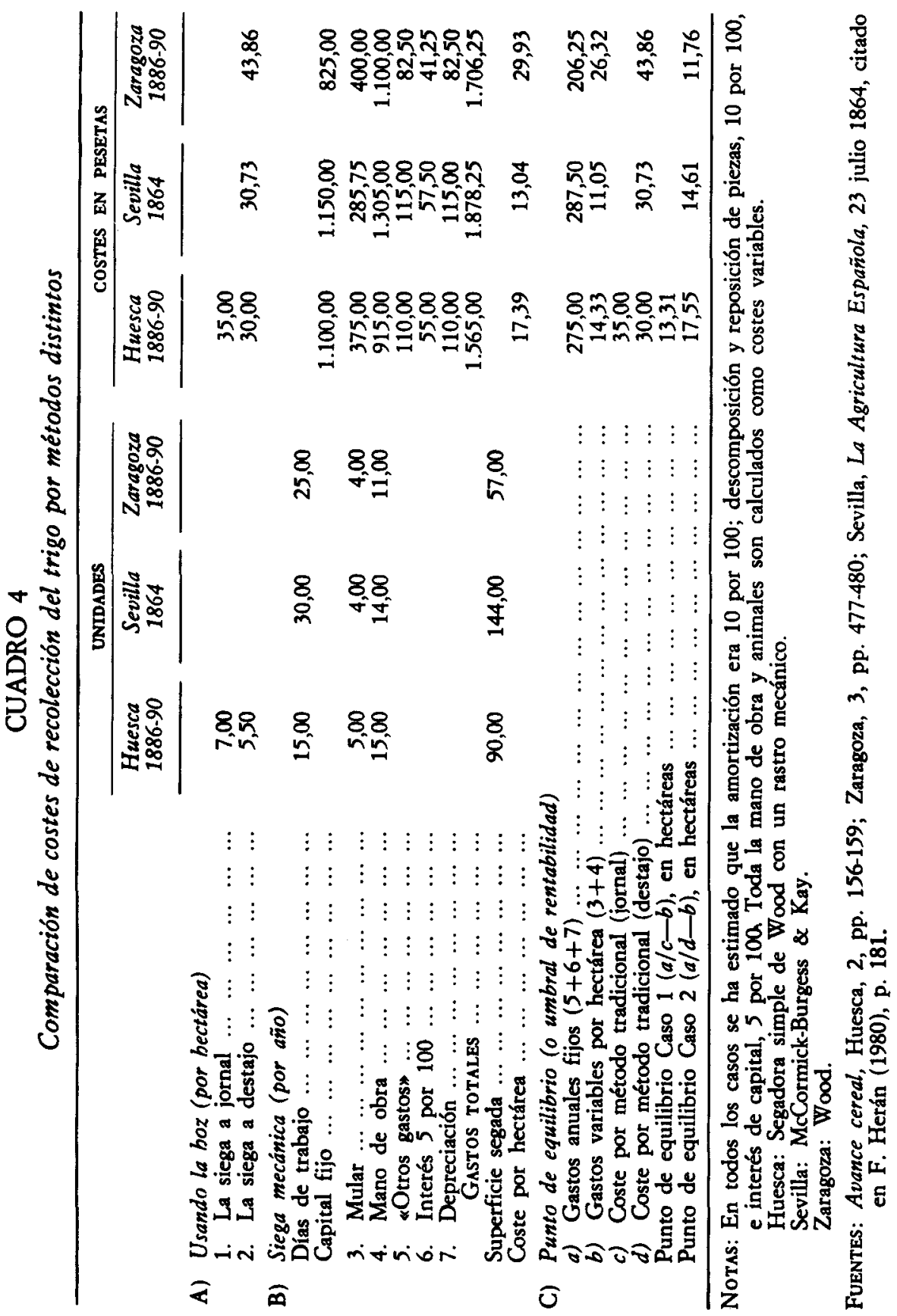


había «un considerable sector manufacturero regional con conexiones de demanda que lo ligaban a la agricultura comercial» ${ }^{36}$, España tenía que importar tecnología y no disponía de un conocimiento mecánico grande, fuera de las ciudades más importantes del país. El Avance cereal señalaba que solamente el constructor Pinagny, de Pamplona, y Elizalde y Compañía habían intentado producir segadoras en España, adaptadas a las condiciones del país, aunque según Serrano, en la importante revista El Progreso Agrícola y Pecuario, en 1901 no había ninguna compañía produciendo maquinaria ${ }^{37}$. Además, y en contraste con el Medio Oeste, donde había mano de obra educada a niveles suficientes para la tecnología usada, y donde las piezas de repuesto eran obtenidas fácilmente, baratas y con rapidez, en España había falta de mecánicos $y$ un retraso de dos meses era normal para obtener cualquier pieza ${ }^{38}$. En una operación a plazo fijo como la cosecha del trigo un retraso de una semana puede ser desastroso, y las dificultades de aplicar esta nueva tecnología a las condiciones locales se reflejan en las noticias de prensa que hablan de maquinaria abandonada ${ }^{39}$.

El segundo punto pertinente al caso español es la naturaleza de la tecnología. En Estados Unidos la segadora fue utilizada extensivamente a mediados del siglo xrx, pero éste es un país donde la tierra era abundante y la fuerza animal era relativamente más barata que la mano de obra. Christensen ha intentado mostrar los precios relativos del trabajo y de los animales en Estados Unidos y Gran Bretaña, y aquí hemos hecho un estudio similar para España (cuadro 5). En todos estos países los precios son muy aproximados ${ }^{40}$. Un precio relativamente más alto de la fuerza animal supondría una tendencia menor a usar máquinas impulsadas por animales.

Los factores críticos de la rentąbilidad de la segadora, suponiendo que no hubiera habido dificultades de tipo mecánico, eran entonces los precios relativos del ganado y de la mano de obra. En este sentido, los dos factores tenían variaciones estacionales en su demanda, y la época de las cosechas de

${ }^{36}$ P. David (1975), p. 198.

37 La segadora de Pinagny fue una McCormick pequeña, para uso con un solo animal, y conocida como La Segadora Navarra, mientras la de Elizalde y Compañía, Nueva Es. pañola, necesitaba cuatro caballerías, trabajando de 2 a 2,5 hectáreas en ocho horas. Avance cereal, Burgos, 1, p. 259, y Navarra, 2, p. 494; Serrano (1901), p. 177.

38 F. Serrano (1901), p. 177.

${ }^{39}$ Las razones no están siempre claras: en León, las dos segadoras en la provincia no funcionan «todos los años»; en Valladolid, la segadora fue abandonada por «no ser fácil la reposición de ciertas piezas que se rompían con frecuencia», y las primeras usadas en Zaragoza, «ya sea por la impericia de los que las manejaban, o ya debido a la complicación de las máquinas, el resultado fue que en su mayor parte fueron relegadas al olvido». Avance cereal, León, 2, p. 231; Valladolid, 3, p. 394, y Zaragoza, 3, p. 478.

to En el caso de España, el animal en el cálculo es la mula, quizás el animal principal en esta época en el cultivo de trigo en la región estudiada aquí, y en Gran Bretaña y Estados Unidos, el caballo. 


\section{CUADRO 5}

Precios relativos de fuerza animal y mano de obra en varios paises, 1860

\begin{tabular}{|c|c|c|c|}
\hline & $\begin{array}{c}\text { Gastos de } \\
\text { manteni- } \\
\text { miento } \\
\text { (semanal) }\end{array}$ & $\begin{array}{l}\text { Salarios } \\
\text { agricolas } \\
\text { (semanal) }\end{array}$ & Costes relativos \\
\hline $\begin{array}{l}\text { G. Bretaña . . } \\
\text { EE. UU. . . . } \\
\text { España . . . }\end{array}$ & $\begin{array}{c}15 \mathrm{~s} \\
\$ 1,03 \\
9,70 \text { ptas. }\end{array}$ & $\begin{array}{l}9 \mathrm{~s} 7 \mathrm{~d} \\
\$ 3,80 \\
5 \text { ptas. }\end{array}$ & $\begin{array}{l}\text { Un animal mantenido al coste de } 1,56 \text { trab. } \\
\text { Un animal mantenido al coste de } 0,27 \text { trab. } \\
\text { Un animal mantenido al coste de } 1,94 \text { trab. }\end{array}$ \\
\hline
\end{tabular}

Fuentes: Gran Bretaña y los Estados Unidos, Christensen (1981), tabla 2. España: animales, Gómez Mendoza (1982), cuadro 3.5; precio de cebada, 12,4 ptas/hl.; salarios, calculado a partir de J. del Moral Ruiz (1979), pp. 76-80.

cereales fue una época de alta demanda. Aunque no parece que hubiera habido un aumento en la demanda de mano de obra (al contrario, si el caso de Sevilla entre 1864 y $1886-90$ es correcto y representativo), hubo una decadencia en la ganadería en los censos de 1865 y 1891 , siendo la fuerza animal disponible por hectárea de tierra cultivada bastante menos a finales del siglo XIX que a mediados del mismo siglo, y menos que durante el primer tercio del siglo xx. Si éste fuera el caso, el cultivador podría haberse visto enfrentado a una alternativa de criar más animales (que tenían un uso limitado fuera de la cosecha y, por tanto, un alto coste) o arriesgar la posibilidad de no encontrar animales para alquilar a precios rentables durante la época de la siega. Volveremos a este argumento cuando consideremos las trilladoras.

Por último, aunque los problemas de reparaciones y el coste relativo de la fuerza animal parecen las más creíbles de las razones de la lenta difusión de las segadoras en España, la situación social del campo en varias partes de España probablemente redujo el ritmo del cambio, por lo menos cuando los beneficios obtenidos por métodos tradicionales eran altos. Pero el retraso en el uso de la segadora en el siglo XIX no fue solamente un fenómeno español, sino europeo. Según Collins, las segadoras en Francia, en 1892, cortaron solamente el 11,5 por 100 de los cereales menores, mientras la cifra en Alemania fue del 6 por 100 (1895); en Holanda, del 1,1 por 100 (1882); en Bélgica, del 4,1 por 100 (1880), y en Gran Bretaña, del 56,4 por 100 (1874), aunque esta última cifra había sido solamente del 6,8 por 100 en $1861^{41}$. A excepción de Gran Bretaña, y en comparación con otros países

${ }^{4}$ Collins calculó una superficie de 24,28 hectáreas (60 acres) por segadora. E. J. T. Col- 
europeos, España no parece muy retrasada en no mecanizar la operación de la siega en estas fechas. Sin embargo, como ha mostrado Collins, la expansión de la superficie de cereales en Europa durante el siglo XIX fue en muchos sitios más rápida que el aumento en la oferta de mano de obra. Para compensar hubo un aumento en la productividad del trabajo en la recolección, con una sustitución de la hoz normal por la hoz pesada y la guadaña en casi toda Europa, con la excepción de Italia, Portugal y España ${ }^{42}$.

El Avance cereal sugiere que la guadaña y el vollant se utilizaban solamente en la región de los Pirineos y áreas limitadas en las provincias de $\mathrm{Ta}$ rragona y Teruel, siendo muy escaso su uso en el resto del país. Como ha mostrado Collins en el caso de Gran Bretaña, el uso de la guadaña significó un ahorro de trabajo en la primera operación (cortando la mies), pero estas ganancias fueron reducidas, por la necesidad de una cantidad de trabajo mayor, en las operaciones secundarias. Así, en Huesca, los costes y necesidades de mano de obra por hectárea eran ${ }^{43}$ :

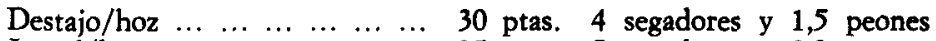

$\begin{array}{lllllllll}\text { Jornal/hoz } & \ldots & \ldots & \ldots & \ldots & \ldots & \ldots & 35 \text { ptas. } 5 \text { segadores y } 2,0 \text { peones }\end{array}$

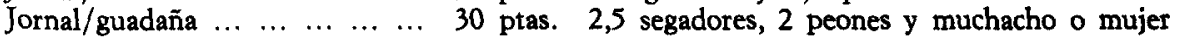

Sin embargo, había otro coste asociado con estos aperos que fue muchas veces decisivo cuando no había escasez de mano de obra. Según el agrónomo de Ciudad Real ${ }^{44}$ :

La guadaña tiene muy poca aceptación en esta provincia porque los labradores aseguran no se agavilla con la facilidad que con la hoz, pues que el segador funciona con las dos manos y no puede recoger los manojos; además, este último instrumento desgrana menos la espiga.

En Huesca, los ahorros conseguidos usando la guadaña en vez de la hoz eran de 5 pesetas por hectárea, y en Lérida de 6 pesetas, cantidades que quedarían eliminadas si las pérdidas del grano excediesen solamente un 3 por 100 de la cosecha ${ }^{45}$. Por eso la introducción de la guadaña nunca fue una

lins (1969), tabla 3. Esto supondría que un 21,62 por 100 de los cereales (trigo, cebada, avena y centeno) en España en 1932 fueron cortados por máquinas.

42 Ibidem, p. 85.

${ }^{43}$ Avance cereal, Huesca, 2, p. 157.

4 Avance cereal, Ciudad Real, 1, p. 377.

45 Avance cereal, Huesca, 2, p. 157; Lérida, 2, pp. 270-271. 
opción seria para la mayoría de los cerealistas. En parte, esto fue también porque no hubo en España un cambio significativo en la relación población activa agraria: superficie cultivada, como ocurrió en varios países de Europa durante esta época.

\section{D) La trilla}

Los métodos tradicionales utilizados en la trilla fueron el pisoteo por medio de caballerías, trillos de ruedas dentadas o de cilindros y, luego, el aventado, generalmente por el apaleo del grano al aire libre, aunque el uso de aventadoras fue aumentando a finales del siglo ${ }^{46}$. El grano, luego, se transportaba a los graneros o mercados.

Las primeras trilladoras de vapor, introducidas en España durante la década de 1860 , no fueron un éxito. La causa, al principio, fue la demanda de los cultivadores españoles de que las máquinas cortasen y machacasen la paja. Esto era distinto a lo que pedían los agricultores del norte de Europa, y reflejaba el aprovechamiento de la paja, como alimento de ganado, en muchas partes de España en lugar del heno ${ }^{47}$. Con este problema superado, el número de máquinas creció, aunque en $1886-90$ parece que virtualmente todas estaban operando en Andalucía, salvo algunas pocas en Aragón. Los costes y el punto de equilibrio han sido calculados a partir del Avance cereal para cinco provincias distintas, y pueden verse en el cuadro 6. Según estos cálculos, el punto de equilibrio en Sevilla, excluidos los costes de reparaciones y conservación, era de 2.440 hectolitros (o 227 hectáreas de trigo sembrada); en Córdoba, de 3.142 hl. (304 ha.); en Cádiz, de 1.776 hl. (262 ha.); en Huesca, de $1.913 \mathrm{hl}$. (172 ha.), y en Zaragoza, de $4.133 \mathrm{hl}$. (366 ha). Con la inclusión de estos otros gastos, a un 10 por 100 del valor de la máquina por año, la superficie que se necesitaba aumentó en Sevilla a unas 378; en Córdoba, a 507; en Cádiz, a 437; en Huesca, a 287, y en Zaragoza, a 610. Según Jaime Reis, en un estudio sobre el Alentejo, fue la superficie cultivada el factor decisivo en la lenta difusión de las máquinas en esta región de Portugal a finales del siglo XIX, más que las cantidades absolutas de capital necesario ${ }^{48}$. El punto de equilibrio dado por Reis en el caso de Portugal fue: «nunca inferiores a 3.200 hectolitros e normalmente superiores a 4.000 hectolitros de cereal,

* Probablemente, las aventadoras fueron usadas para superar los retrasos causados por la falta del viento más que por cuestiones de costes. Por ejemplo, Avance cereal, Huesca, 2, pp. 159-160.

${ }^{47}$ El Fomento Agrícola en Jerez de la Frontera envió a Ipswich grandes cantidades de mies de trigo, y los ensayos de Ransomes en Sevilla en el año 1865 tuvieron éxito. E. Abela y Sanz (1877), pp. 535-552.

J. Reis (1982), p. 407. 


\section{CUADRO 6}

Comparación de costes de la trilla usando métodos distintos

\begin{tabular}{|c|c|c|c|c|c|c|}
\hline \multirow[b]{2}{*}{ A) } & & Cádiz & Cárdoba & Sevilla & Huesca & Zaragoza \\
\hline & \multicolumn{6}{|l|}{ Trilladora de vapor } \\
\hline & Horas de trabajo $\ldots \ldots \ldots \ldots \ldots$ & 585 & 420 & 384 & 400 & 1.000 \\
\hline & 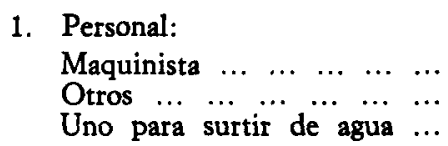 & $\begin{array}{r}180,00 \\
1.147,50\end{array}$ & $\begin{array}{r}300,00 \\
1.110,00 \\
360,00\end{array}$ & $\begin{array}{r}272,00 \\
1.824,00 \\
160,00\end{array}$ & $\begin{array}{l}225,00 \\
700,00 \\
315,00\end{array}$ & $\begin{array}{r}500,00 \\
2.000,00 \\
200,00\end{array}$ \\
\hline & $\begin{array}{cccccccc}\text { Total } & \ldots & \ldots & \ldots & \ldots & \ldots & \ldots & \ldots\end{array}$ & $1.327,50$ & $1.770,00$ & $2.256,00$ & $1.240,00$ & $2.700,00$ \\
\hline
\end{tabular}

2. La máquina:

\begin{tabular}{|c|c|c|c|c|c|}
\hline 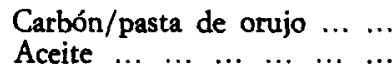 & $\begin{array}{r}1.350,00 \\
67,50\end{array}$ & & $\begin{array}{l}471,00 \\
104,00\end{array}$ & $\begin{array}{l}600,00 \\
180,00\end{array}$ & $\begin{array}{r}2.500,00 \\
400,00\end{array}$ \\
\hline Total & $1.417,50$ & $1.350,00$ & 575,00 & 780,00 & $2.900,00$ \\
\hline
\end{tabular}

3. Anuales:

\begin{tabular}{|c|c|c|c|c|c|}
\hline $\begin{array}{llll}\text { Valor de la máquina } & \ldots & \ldots \\
\text { Interés } 5 \text { por } 100 & \ldots & \ldots & \ldots \\
\text { Amortización } 10 \text { por } 100 & \ldots\end{array}$ & $\begin{array}{r}10.000,00 \\
500,00 \\
1.000,00\end{array}$ & $\begin{array}{r}750,00 \\
1.500,00\end{array}$ & $\begin{array}{r}675,00 \\
1.350,00\end{array}$ & $\begin{array}{r}675,00 \\
1.350,00\end{array}$ & $\begin{array}{r}675,00 \\
1.350,00\end{array}$ \\
\hline $\begin{array}{cccccccc}\text { Total } & \ldots & \ldots & \ldots & \ldots & \ldots & \ldots & \ldots\end{array}$ & $1.500,00$ & $2.250,00$ & $2.025,00$ & $2.025,00$ & $2.025,00$ \\
\hline TotaL $(1+2+3) \ldots \ldots$ & $4.245,00$ & $5.370,00$ & $4.856,00$ & $4.045,00$ & $7.625,00$ \\
\hline $\begin{array}{c}\text { blitros de } \operatorname{trigo} / \text { año } \\
\begin{array}{ccccc} & \ldots \\
\text { hectolitro } & \ldots & \ldots & \ldots & \ldots \\
\text { variable } & \ldots & \ldots & \ldots & \ldots\end{array}\end{array}$ & $\begin{array}{r}6.525 \\
0,65 \\
0,42\end{array}$ & $\begin{array}{r}9.942 \\
0,54 \\
0,31\end{array}$ & $\begin{array}{r}4.224 \\
1,15 \\
0,67\end{array}$ & $\begin{array}{r}2.400 \\
1,69 \\
0,84\end{array}$ & $\begin{array}{r}7.000 \\
1,09 \\
0,80\end{array}$ \\
\hline $\begin{array}{l}\text { e por métodos tradicionale } \\
\text { hectolitro) }\end{array}$ & 1,27 & 1,03 & 1,50 & 1,90 & 1,29 \\
\hline $\begin{array}{l}\text { E. Caso 1, en hectolitros } \\
\text { E. Caso 2, en hectolitros. } \\
\text { imiento hectolitros/hectárea. } \\
\text { E. Caso 1, en hectáreas ... } \\
\text { E. Caso 2, en hectáreas ... }\end{array}$ & $\begin{array}{r}1.766,14 \\
2.943,56 \\
6,74 \\
262,04 \\
436,73\end{array}$ & $\begin{array}{r}3.141,67 \\
5.236,11 \\
10,33 \\
304,13 \\
506,88\end{array}$ & $\begin{array}{r}2.440,40 \\
4.067,33 \\
10,76 \\
226,80 \\
378,00\end{array}$ & $\begin{array}{r}1.913,39 \\
3.188,98 \\
11,11 \\
172,22 \\
287,04\end{array}$ & $\begin{array}{r}4.132,65 \\
6.887,76 \\
11,29 \\
366,05 \\
610,08\end{array}$ \\
\hline
\end{tabular}

Notas: En el Caso 1 no se incluyen gastos por reparación y conservación. En el Caso 2, éstos están incluidos a un valor de 10 por 100 de la máquina.

El valor de la máquina en Zaragoza es una estimación. Otro beneficio que no está incluido aquí es la mayor cantidad y calidad del grano y la paja.

Por métodos de cálculo, el punto de equilibrio es diferente aquí para la provincia de Sevilla que el dado en la fuente $(1.500 \mathrm{hl}$.).

Funntes: Avance cereal, Cádiz, 1, pp. 299-300; Córdoba, 1, pp. 419-422; Sevilla, 3, pp. 145-151; Huesca, 2, pp. 159-162, y Zaragoza, 3, pp. 481-486. 
sendo necessário, segundo certos autores, atingir-se os 6.000 ou 7.000 hectolitros" ${ }^{49}$. Por supuesto, los costes de producción en Portugal y en España eran distintos, pero en todos los ejemplares del cuadro 6 la cantidad del trigo trillado durante el año fue superior a 4.000 hectolitros en Andalucía. Los altos niveles de capital y cantidades de cereales necesarios, además de tratarse de una máquina mucho más complicada que la segadora, explican su ausencia en la mayor parte de España. Sin embargo, en Sevilla, y quizás en otras provincias de Andalucía, su importancia en estas fechas era mucho mayor que la de las segadoras ${ }^{50}$. Para intentar explicar esta mayor difusión, los impactos del uso de las segadoras y las trilladoras de vapor sobre el uso de los factores de inputs, mano de obra y la fuerza animal, véase, para Sevilla, el cuadro 7.

\section{CUADRO 7}

Estimación de demanda para trabajo y ganado en la siega y la trilla, Sevilla, $1886-90$

(Superficie sembrada: trigo, 300 hectáreas; cebada, 150)

\begin{tabular}{|c|c|c|c|c|c|c|c|c|}
\hline & \multicolumn{6}{|c|}{ NUMERO DE DIAS DE TRABAJO } & \multicolumn{2}{|c|}{ TOTAL COSTES } \\
\hline & Labor & Indice & Por ba. & Gan. & Indice & Por ba. & Total & Indice \\
\hline 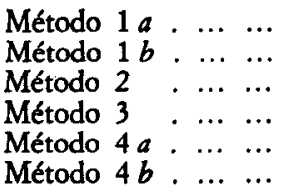 & $\begin{array}{l}4.798 \\
3.595 \\
3.670 \\
2.779 \\
4.471 \\
3.268\end{array}$ & $\begin{array}{r}100 \\
75 \\
77 \\
58 \\
93 \\
68\end{array}$ & $\begin{array}{r}10,66 \\
7,99 \\
8,16 \\
6,18 \\
9,94 \\
7,26\end{array}$ & $\begin{array}{r}2.134 \\
2.134 \\
2.495 \\
1.612 \\
914 \\
914\end{array}$ & $\begin{array}{r}100 \\
100 \\
117 \\
76 \\
43 \\
43\end{array}$ & $\begin{array}{l}4,74 \\
4,74 \\
5,54 \\
3,58 \\
2,03 \\
2,03\end{array}$ & $\begin{array}{l}19.332 \\
17.658 \\
16.111 \\
15.733 \\
18.954 \\
17.280\end{array}$ & $\begin{array}{r}100 \\
91 \\
83 \\
81 \\
98 \\
89\end{array}$ \\
\hline
\end{tabular}

$1 a=$ siega con hoz a jornal; trillos de cilindros.

$1 b=$ siega con hoz a destajo; trillos de cilindros.

2 =siega con 4 segadoras; trillos de cilindros.

3 = siega con 4 segadoras; trilla con trilladora.

$4 a=$ siega con hoz a jornal; trilla con trilladora.

$4 b=$ siega con hoz a destajo; trilla con trilladora.

Notas: Todas las operaciones, desde la siega hasta la distribución del grano (hasta una distancia de 2 kilómetros), están incluidas.

El número de trabajadores a destajo, calculado como un 60 por 100 del tiempo a jornal.

Fuente: Calculado a partir del Avance cereal (1891), pp. 143-150.

49 Ibidem, p. 405.

so Avance cereal, Sevilla, 3, pp. 145 y 147. 
En una finca hipotética, con unas 300 hectáreas de trigo y 150 hectáreas de cebada sembrada, el sistema más rentable de hacer la siega y la trilla, según el cuadro 7 , era con el método 3 , o sea, usando cuatro segadoras y una trilladora de vapor, y el más caro recogiendo la cosecha con hoz a jornal y haciendo la trilla con trillos de cilindros. Desde el punto de vista de los costes totales, parece que los cambios en los métodos de la recolección hubieran sido más rentables que los cambios en el sistema de la trilla. Sin embargo, la demanda de ganado varía en el cuadro 7 con una gran intensidad, desde un minimo de 2,03 animales/ha. en los costes $4 a$ y $4 b$ a 5,5 animales en el caso 2 . Como hemos indicado anteriormente, el uso de las segadoras aumentó el uso del ganado, y aquí se puede ver que las trilladoras lo redujeron. Como la cosecha y la trilla se hacían en épocas de alta demanda de animales de tiro, las posibilidades de alquilarlos se reducían y el coste de mantener, por ejemplo, otras seis mulas para solamente dos meses de trabajo al año hubiera sido de unas 3.500 pesetas al año ( 3.350 fijas, 150 variables). Así, el ganado solamente podía ser considerado como un coste variable si había otras posibilidades de trabajo durante el año. Como conclusión, la falta de una fuerza de energía barata, probablemente, redujo la demanda de las segadoras, y un remedio posible a este problema fue la introducción de la trilladora en determinadas fincas.

\section{CONCLUSION}

La prensa agrícola, a finales del siglo xIx, muestra que muchos de los avances en la maquinaria agrícola eran conocidos en España y que algunas veces esta tecnología había sido ensayada, bien por iniciativa de un individual, bien por organizaciones gubernamentales. El problema que hay que explicar en el caso español es por qué la difusión de la maquinaria tardó tanto tiempo en introducirse en el país, ya que no fue por ignorancia de la tecnología extranjera.

Este artículo ha surgido de una consideración importante acerca de si la tecnología era la apropiada, dadas las condiciones locales de producción. Como la mayor parte de la maquinaria desarrollada a finales del siglo XIX y a principios del $x \mathbf{x}$ en el norte de Europa y Estados Unidos intentaba ahorrar mano de obra, factor de producción que no era escaso en España, no es una sorpresa encontrar poco entusiasmo en los agricultores españoles por la nueva tecnología. Aunque podemos suponer que cada agricultor querría reducir sus gastos de mano de obra (o aumentar su ocio en el caso de pequeños propietarios), las posibilidades de hacerlo eran limitadas si no disponían de otra fuerza de 
energía barata. En este caso, la interrelación de los cambios era importante, y aquí se muestra que el mayor ritmo de producción de la mula podría compensar el aumento en la fuerza animal, asociado con la introducción de la vertedera y la introducción de las trilladoras de vapor, ahorrando ganado que podría ser utilizado en la siega en Andalucía. Cada agricultor en España tenía sus propios costes de producción que excluían la existencia de una forma única y óptima de cultivar para todos los productores españoles.

La segunda dificultad para la introducción de maquinaria era la dificultad de su operación por falta de mecánicos y piezas de repuesto. Este tipo de problemas afectaron a la tecnología a todos niveles, como muestra la cita de Muñoz Rubio (véase p. 281), y fue más importante cuando la operación tenía una limitación de tiempo. Por otra parte, el retraso en la adopción de maquinaria afectó negativamente a la educación técnica de la fuerza laboral en la economía.

La consideración predominante para el agricultor hubiera sido distinguir la tasa de beneficio para las distintas innovaciones posibles, factor importante dados los pequeños recursos disponibles para la inversión. El cálculo de las tasas de beneficio hubiera sido difícil, pero un cálculo muy aproximado hecho por agricultor a base de la información dada en el cuadro 2 muestra que un aumento de un 10 por 100 en los ingresos en provincias tan diversas como Córdoba o Valladolid hubiera sido el equivalente de ahorrar la mitad de todos los costes asociados con la siega y la trilla. La inversión en carros de estiércol quizá hubiera dado mejores beneficios que una segadora extranjera.

En definitiva, fue la protección arancelaria lo que aumentó los ingresos, y ello es una de las características más importantes en la economía triguera española en el medio siglo antes de la guerra civil. En consecuencia, la producción fue casi enteramente para el mercado nacional, y en 1900 dos tercios, aproximadamente, de la población activa trabajaba todavía en la agricultura. Entonces, como había una demanda segura para sus productos y una oferta amplia de mano de obra, no es extraño encontrar poco interés en la maquinaria estadounidense. Según la media de las provincias en el cuadro 2 , un movimiento en el precio del trigo de una peseta por hectolitro era el equivalente de más del 20 por 100 de todos los gastos de la siega y la trilla. Esta situación en el trigo contrasta con otros aspectos de la agricultura española, como el naranjo en Valencia o la producción del aceite de oliva. En ambos casos, un nivel de inversión relativamente alto era esencial para la creación de nuevos mercados fuera de España. Más bien que sugerir que el sector triguero estaba más retrasado que otros sectores de la agricultura española, quizá una explicación mejor sería la cuestión de la demanda final, que aparece como otro factor para explicar la persistencia de la tecnología tradicional, todavía encon- 
trada extensamente en vísperas de la guerra civil e incluso hasta bien entrada la época franquista.

\section{APENDICE}

\section{MAPA 1. Los rendimientos de trigo por bectárea (QM), $1886-90$}

Dado que algunas veces las estimaciones de rendimientos a finales del siglo XIX no son muy fiables, hemos supuesto que la cifra del Avance cereal de 1886-90 no podía estar fuera de una banda de $75-115$ por 100 de los rendimientos en 1906-10. Cuando están más bajas o altas, el máximo o mínimo de la banda ha sido utilizado. Para mayor exactitud, en las provincias de Jaén, Logroño, Málaga y Zaragoza, la época está extendida hasta 1906-15. Los rendimientos para los años son de Manuel de Torres (1944), pp. 275-285, y se refieren a secano.

\section{CUADRO 2}

En el Avance cereal hay varias cálculos para la producción del trigo, usando una variedad de rotaciones y rendimientos en cada provincia. En todos los casos, la rotación utilizada aquí es el año y vez o al tercio, y el ejemplo del rendimiento elegido, lo que es más representativo de la provincia. Para Almería, Cádiz y Salamanca, dos tipos de costes están utilizados, dado que todos caen dentro de nuestro criterio.

$\mathrm{Ha}$ sido necesario excluir los costes y beneficios de otros cultivos en la rotación en las provincias de Córdoba, Málaga, Segovia y Sevilla.

Con respecto a los ingresos, los rendimientos en los costes del Avance cereal han sido multiplicados por el precio medio para los años 1886-87 a 1890-91 - N. Sánchez-Albornoz (1975), pp. 162-165, y GEHR (1980), pp. 185-186 - El ratio de paja : grano es del Avance cereal, cuando la cifra está dentro de una banda de 115 y 75 por 100 de los años 1903-12; cuando está fuera de esta banda, el máximo o mínimo ha sido utilizado. Para los precios de la paja el mismo método es utilizado, aunque en este caso la banda es 75 y 125 por 100 . De menos importancia para el agricultor fueron los ingresos de pastos en el rastrojo, barbecho y erial. Cuando no hay una cifra en la fuente, una cifra de 2 ptas/ha. ha sido usada.

Los costes incluyen las labores, la siembra y semilla, escarda, abonos/estiércol y sus costes de aplicación, la recolección, trilla y aventado. La renta, impuestos y amortización de edificios, animales y herramientas quedan excluidos. Toda la mano de obra ha sido medida en dinero, aunque, por supuesto, en muchos sitios estaba proporcionada por mano de obra familiar. 


\section{BIBLIOGRAFIA}

Abela y SANZ, E. (1877): «La trilla mecánica en España», en Gaceta Agrícola del Ministerio de Fomento, vol. 3, pp. 535-552.

Bernal, A. M. (1984): «Economía Agraria en la Andalucía Contemporánea», en Papeles de Economía Española: La nueva cara de la bistoria económica de España, Madrid, pp. 281-297.

Binsw Anger, H. P. (1984): Agricultural Mechanization: A Comparative Historical Perspective, World Bank Staff Working Papers no. 673, Washington.

Binswanger, H. P., y RutTAN, V. W. (1978): Induced Innovation, The John Hopkins University Press, Baltimore y Londres.

Christensen, P. (1981): «Land Abundance and Cheap Horsepower in the Mechanization of the Antebellum United States Economy», en Explorations in Economic History, 18 , pp. 309-329.

Colins, E. J. L. (1969): «Labour Supply and Demand in European agriculture, 18001880 m, en Jones, E. L., y Woolf, S. J.: Agrarian Change and Economic Development. The Historical Problems, Methuen \& Co., Londres.

David, P. (1975): Tecbnical Choice, Innovation and Economic Growth, Cambridge University Press, Londres.

Dirección General de Agricultura, Industria y Comercio (1891): Avance estadístico del cultivo cereal y leguminosas asociados en España, Madrid, 3 .vols.

- (1892): La Ganadería en España. Avance sobre la riqueza pecuaria en 1891, Madrid, 5 vols.

Exposición Vinfcola Nacional (1878-79): Estudio sobre la... de 1877, Madrid.

GALLEGO, D. (1986): «Transformaciones técnicas de la agricultura española en el primer tercio del siglo $\mathrm{xx}$, en Garrabou, Barciela y Jiménez Blanco (eds.): Historia agraria de la España contemporánea, tomo 3, Editorial Crítica, Madrid.

Gómez Mendoz^, A. (1982): Ferrocarriles y cambio económico en España (1855-1913), Alianza Universidad, Madrid.

Grupo de Estudios de Historia RuRal (1980): Los precios del trigo y la cebada en España, 1891-1907, Banco de España (Servicio de Estudios), Madrid.

- (1983): «Notas sobre la producción agraria española, 1891-1931», en RevisTa DE His. TORIA ECONÓMICA, núm. 2, pp. 185-252.

- (1985): «Evolución de la superficie cultivada de cereales y leguminosas en España, 1886-1935», en Martín Aceña y Prados de la Escosura (eds.): La Nueva Historia Económica en España, Tecnos, pp. 52-70.

Herর́N, F. (1980): Tierra y parentesco en el campo sevillano. La revolución agrícola del siglo XIX, Ministerio de Agricultura, Madrid.

Jiménez BLANCo, I. (1986): “Introducción», en Garrabou, Barciela y Jiménez Blanco (eds.): Historia agraria de la España contemporánea, tomo 3, Editorial Crítica, Madrid,

Junta General de Estadistica (1868): Censo de la ganadería de España, según el recuento verificado en 24 de septiembre de 1865, Madrid.

LEWIs, W. A. (1978): Growth and Fluctuations 1870-1913, Allen \& Unwin, Londres.

Llopis AgElan, E. (1986): «El agro castellano en el siglo XVIr: ¿depresión o "reajustes y readaptaciones"?», en Revista dE Historia EconómicA, núm. 1, pp. 11-37.

MANUEL DE TORRES (1944): El problema triguero y otras cuestiones fundamentales de la Agricultura española, Madrid.

Ministerio de Agricultura, Dirección General de Agricultura (1933): Anuario estadístico de las producciones agrícolas. Año 1932, Madrid.

- (1934): «La ganadería en España», en Tres estudios económicos. Apéndice al Anuario estadístico de las producciones agricolas. Año 1933, Madrid.

Moral RuIz, J. del (1979): La agricultura española a mediados del siglo XIX (1850-1870), Ministerio de Agricultura, Madrid.

MuÑoz y Rubio, P. (1886): El Arado, Madrid. 
NoRiega y Abascal, E. (1897): La tierra labrantía y el trabajo agricola en la provincia de Sevilla, Madrid.

Prados DE LA Escosura, L. (1986): Output and Productivity in Spanish Agriculture: 1800-1910, comunicación presentada al II Seminario de Historia Económica Cuantitativa, Centro Ortega y Gasset, Madrid.

REIS, J. (1982): «Latifúndio e prōgresso técnico: a difusāo da debulha mecânica no Alentejo, 1860-1930», en Análise Social, vol. XVIII (71), pp. 371-433.

SánC HEZ-AlboRnoz, N. (1975): Los precios agrícolas durante la segunda mitad del siglo XIX, vol. 1: "Trigo y Cebada», Banco de España (Servicio de Estudios), Madrid.

Serrano, F. (1901): "Consejos acerca de la siega con máquinas segadoras en España", en El Progreso Agrícola y Pecuario; núms. 237, 239 y 240, pp. 165-166, 177-178 y $187-188$.

Simpson, J. (1985): Agricultural Growth and Technical Change: The Olive and Vine in Spain, 1860-1936, Unpublished Ph. D. Thesis, University of London.

Zapata Blanco, S. (1986): La producción agraria de Extremadura y Andalucía occidental, 1875-1935, tesis doctoral 53/86, Editorial de la Universidad Complutense de Madrid. 